\title{
Силиплант в системе защиты огурца против мучнистой росы
}

\author{
Siliplant in the cucumber protection system against powdery mildew
}

Алексеева К.Л., Сметанина Л.г.

\section{Аннотация}

Мучнистая роса - опасное заболевание огурца защищенного грунта, вызывающее значительные потери урожая, особенно в условиях эпифитотийного развития. Возбудитель мучнистой росы Oidium erysiphoides Fr. способен быстро формировать расы, резистентные к применяемым фунгицидам, поэтому важное значение имеют альтернативные средства защиты, среди которых наиболее известны препараты на основе рапсового масла (рапсол, рапсол-экстра), минеральные соли (фосфит калия, бикарбонат калия, кальциевая селитра), препараты на основе биоактивного кремния. В статье представлены результаты испытания кремнийсодержащего удобрения Силиплант против мучнистой росы огурца в условиях пленочных теплиц Московской области на естественном инфекционном фоне. Исследования проведены на огурце сорта Вязниковский. Растения опрыскивали при появлении первых симптомов мучнистой росы и далее с интервалом десять дней. Схема опыта включала различные нормы расхода Силипланта $(0,8 ; 1,0 ; 1,2$ л/ га) и Силиплант в сочетании с Фармайодом (0,02\%). Контролем служил вариант без обработки, эталоном - обработка фунгицидом Топаз (1 л/га). Установлено, что при норме расхода Силипланта 1,01,2 л/га развитие мучнистой росы огурца снижается на 65,3$68,1 \%$ по сравнению с контролем. Баковая смесь Силипланта и Фармайода $(0,02 \%)$ повышает биологическую эффективность обработок до 76,8\%. Под воздействием обработок отмечено повышение урожайности огурца на 8,5-17,0\% к контролю. Применение Силипланта в норме 1,0-1,2 л/га увеличивает содержание витамина C и сахаров в плодах огурца соответственно на $19,6-22,5 \%$ и 41,7-53,0\%. Полученные результаты позволяют заключить, что Силиплант может быть использован как элемент комплексной системы защиту огурца от мучнистой росы. Наиболее эффективную защиту огурца от мучнистой росы обеспечили обработки растений Силипланта в норме 1,2 л/га с добавлением Фармайода (0,02\%).

Ключевые слова: кремнийсодержащее удобрение Силиплант, огурец, пленочные теплицы, мучнистая роса, защита растений.

Для цитирования: Алексеева К.Л., Сметанина Л.Г. Силиплант в системе защиты огурца против мучнистой росы // Картофель и овощи. 2020. №5. C. 25-27. https://doi.org/10.25630/ PAV.2020.64.36.005

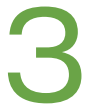
начительный ущерб культуре огурца в защищенном грунте наносит мучнистая роса (возбудители Oidium erysiphoides Fr., телеоморфа Erysiphe cichoracearum DC f. cucurbitacearum Pot. и Sphaerotheca fuliginea Pol f. cucurbitae Jacz), вызывающая появление на листьях белого паутинистого налета. По мере развития болезни пораженные листья желтеют и отмирают, что приводит к сокращению площади ассимиляционной поверхности, нарушению процессов завязывания и созревания плодов. Растения теряют большое

\author{
Alexeeva K.L., Smetanina L.G.
}

\section{Abstract}

Powdery mildew is a dangerous disease of protected ground cucumber that causes significant crop losses, especially in conditions of epiphytotic development. The causative agent of powdery mildew is Oidium erysiphoides Fr. It is able to quickly form races that are resistant to the applied fungicides, so alternative means of protection are important, among which the most famous are preparations based on rapeseed oil (rapsol, rapsol-extra), mineral salts (potassium phosphite, potassium bicarbonate, calcium nitrate), preparations based on bioactive silicon. The article presents the results of testing the silicon-containing fertilizer Siliplant against cucumber powdery mildew in the conditions of film greenhouses in the Moscow region on a natural infectious background. Research was conducted on Vyaznikovsky hybrid cucumber. Plants were treated by spraying when the first symptoms of powdery mildew were seen and then it was done at intervals of 10 days. The scheme of the experiment included different consumption rates of Siliplant $(0.8 ; 1.0 ; 1.2 \mathrm{I} / \mathrm{ha})$ and Siliplant in combination with Farmayod $(0.02 \%)$. Variant without treatment served as the control, the standard-treatment - spraying of Topaz fungicide $(1 \mathrm{l} / \mathrm{ha})$. It was found that at the rate of Siliplant consumption of $1.0-1.2 \mathrm{l} / \mathrm{ha}$, the development of cucumber powdery mildew decreases by $65.3-68.1 \%$ compared to the control. The tank mixture of Siliplant and Farmayod $(0.02 \%)$ increased the biological efficiency of treatments to $76.8 \%$. Under the influence of treatments, there was an increase in cucumber yield by $8.5-17.0 \%$ compared to the control. The use of Siliplant in the norm of 1.0-1.2 I/ha increases the content of vitamin $\mathrm{C}$ and sugars in cucumber fruits by 19.6$22.5 \%$ and $41.7-53.0 \%$, respectively. The results obtained allow us to conclude that Siliplant can be used as an element of a complex system for protecting cucumbers from powdery mildew. The most effective protection means from powdery mildew was provided by processing Siliplant on cucumber plants at a rate of $1.2 \mathrm{l} /$ ha with the addition of farmayod $(0.02 \%)$.

Key words: silicon-containing fertilizer Siliplant, cucumber, film greenhouses, powdery mildew, plant protection.

For citing: Alexeeva K.L., Smetanina L.G. Siliplant in the cucumber protection system against powdery mildew // Potato and vegetables. 2020. No5. Pp. 25-27. https://doi.org/10.25630/PAV.2020.64.36.005 (In Russ.) количество воды и засыхают. При отсутствии эффективной системы защиты болезнь быстро распространяется в теплице, приобретает эпифитотийный характер, что приводит к сокращению периода вегетации огурца, снижению выхода продукции и ухудшению качества плодов.

Для снижения вредоносности мучнистой росы в теплице используют различные методы. При невысокой степени поражения растений применяют биопрепараты (Алирин-Б, Бактофит, Гамаир, Псевдобактерин-2) [1], на жестком инфекционном фоне - химические фунгициды. В настоящее время против мучнистой росы огурца защищенного грунта зарегистрированы Привент, Полар 50, Топаз, Квадрис, Тиовит Джет. Однако возбудитель мучнистой росы отличается высоким уровнем изменчивости и способностью быстро формировать резистентные расы. Снижение эффективности действия препаратов требует усиления пестицидной нагрузки, что приводит к ухудшению фитосанитарного состояния теплиц и способствует накоплению остаточных количеств 
Таблица 1. Эффективность применения кремнийсодержащего удобрения Силиплант против мучнистой росы огурца, 2018-2019 годы

\begin{tabular}{|c|c|c|c|c|c|c|c|}
\hline \multirow{2}{*}{ Вариант } & \multirow{2}{*}{ Степень развития, \% } & \multirow{2}{*}{$\begin{array}{c}\text { Биологическая эф- } \\
\text { фективность, \% }\end{array}$} & \multicolumn{3}{|c|}{ Урожайность, кг/м² } & \multicolumn{2}{|c|}{ Прибавка к контролю } \\
\hline & & & 2018 & 2019 & средняя & $\mathrm{K} \Gamma / \mathrm{M}^{2}$ & $\%$ \\
\hline Контроль & 65,2 & - & 9,6 & 9,2 & 9,4 & - & \\
\hline Топаз, 1,0 л/га & 14,2 & 78,2 & 11,2 & 10,6 & 10,9 & 1,5 & 15,9 \\
\hline Силиплант, 0,8 л/га & 31,2 & 52,1 & 10,1 & 10,3 & 10,2 & 0,8 & 8,5 \\
\hline Силиплант, 1,0 л/га & 22,6 & 65,3 & 10,8 & 10,6 & 10,7 & 1,3 & 13,8 \\
\hline Силиплант, 1,2 л/га & 20,8 & 68,1 & 11,1 & 10,5 & 10,8 & 1,4 & 14,9 \\
\hline $\begin{array}{l}\text { Силиплант, 1,2 л/га + } \\
\text { Фармайод, 0,02\% }\end{array}$ & 15,1 & 76,8 & 11,3 & 10,7 & 11,0 & 1,6 & 17,0 \\
\hline $\mathrm{HCP}_{05}$ & & & 1,5 & 1,3 & & & \\
\hline
\end{tabular}

пестицидов в продукции. В качестве альтернативных способы защиты огурца от мучнистой росы известны препараты на основе рапсового масла (Рапсол, Рапсол-экстра) [2], минеральные соли - фосфит калия, бикарбонат калия, кальциевая селитра $[3,4]$, а также препараты на основе активных форм кремния [5, 6]. К последним относится Силиплант, который уже более десяти лет успешно применяют в современных агротехнологиях, как удобрение, содержащее биоактивный кремний и микроэлементы в хелатной форме [7]. Силиплант обладает антистрессовыми и фунгицидными свойствами. Механизм его действия заключается в том, что кремний повышает механическую прочность растительных клеток и способствует повышению устойчивости растений к поражению фитопатогенами. Наряду с этим кремний оказывает непосредственное влияние на фитопатогены, останавливает их рост [8].

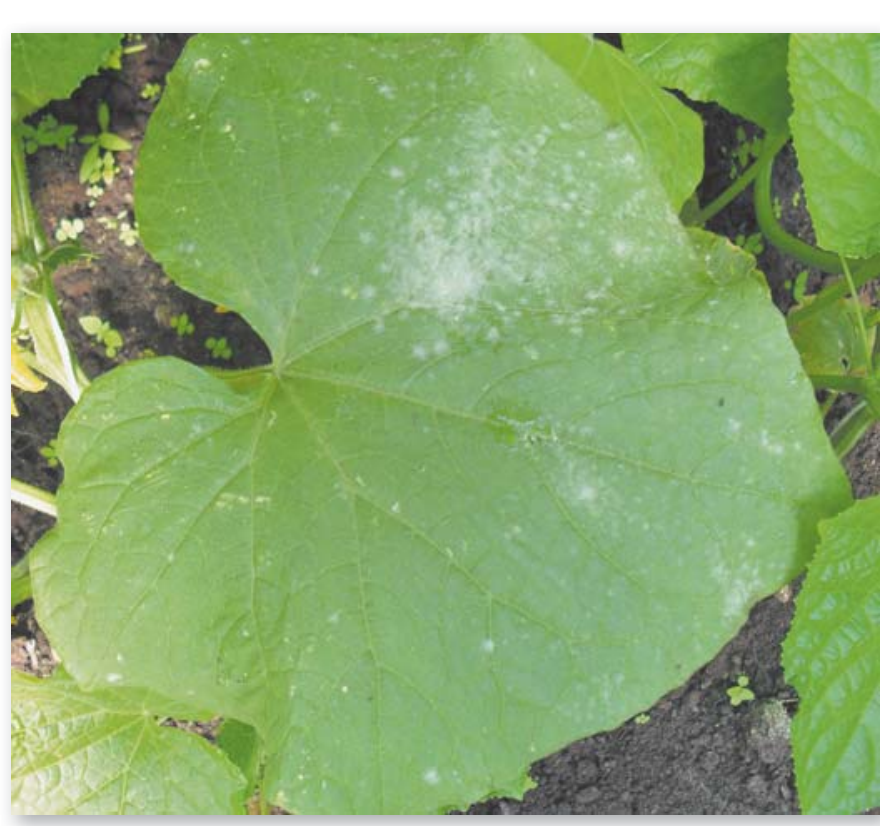

Симптомы мучнистой росы на листовой пластинке огурца
Цель исследований: оценить эффективность применения препарата Силиплант против мучнистой росы на огурце в защищенном грунте, выявить его оптимальные дозы.

Условия, материалы и методы исследований

Эффективность

применения

Силипланта против мучнистой росы огурца изучали в 2018-2019 годах на базе ВНИИО - филиала ФГБНУ ФНЦО (Московская область, Раменский район) на естественном инфекционном фоне в условиях грунтовых пленочных теплиц. В опытах использовали огурец сорта Вязниковский. Высадка рассады - в третьей декаде мая. Густота посадки огурца составляла 4,2 растения на $1 \mathrm{~m}^{2}$. Уход за культурой проводился в соответствии с принятой технологией. Опыты закладывали в соответствии со стандартной методикой [8]. Схема опыта включала различные нормы расхода Силипланта $(0,8 ; 1,0$; 1,2 л/га) и Силиплант в сочетании с Фармайодом ( $0,02 \%$ ) . Контролем служил вариант без обработки, эталоном обработка фунгицидом Топаз (1 л/га). Обработки проводили трехкратно путем опрыскивания растений. Первая обработка - при появлении первых симптомов мучнистой росы, последующие - с интервалом десять дней. Расход рабочей жидкости 400 л/га. Учеты распространенности и развития мучнистой росы проводили по ме- тодике ВИЗР [7]. Степень поражения листовой поверхности огурца мучнистой росой оценивали по 9-балльной шкале, где 0 баллов - признаков поражения нет, 8 баллов - растение погибло. Повторность опыта четырехкратная. Площадь учетной

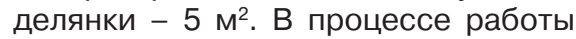
проводили фенологические наблюдения и учет урожая по вариантам опыта. Качество продукции оценивали по стандартным методикам: содержание сухого вещества - термостатно-весовым методом, содержание сахаров - методом Бертрана, содержание витамина С - методом И.К. Мурри.

\section{Результаты исследований}

Как показали исследования, в 2018 году первые симптомы мучнистой росы на листьях огурца появлялись в третьей декаде июля, в 2019 году - во второй декаде июля в виде отдельных пятен с белым паутинистым налетом диаметром 2-3 мм (рис.). В контрольном варианте без обработок наблюдали активное развитие мучнистой росы. В наибольшей степени болезнь поражала более старые листья в нижней части растения. Пятна на листьях постепенно увеличивались в диаметре, срастались между собой, покрывались обильным мучнистым налетом, который представляет собой поверхностный мицелий гриба и его конидиальное спороношение. Через пять недель после появления первых симптомов степень развития мучнистой росы в контроле достигала 65,2\%. На вариантах с применением Силипланта эффективность его действия была заметна через 1-2 дня после обработок. На поверхности пораженных листьев оставались хлоротичные пятна, а белый налет исчезал, что свидетельствует о подавлении развития инфекционных структур гриба - конидиальных цепочек. Под влиянием препарата замедлялось появление новых пятен 
Таблица 2. Влияние обработок Силиплантом на качество плодов, 2018-2019 годы

\begin{tabular}{|c|c|c|c|c|c|c|}
\hline \multirow{2}{*}{ Вариант } & \multirow{2}{*}{$\begin{array}{c}\text { Сухое } \\
\text { вещество, } \\
\%\end{array}$} & \multirow{2}{*}{$\begin{array}{c}\text { Витамин } \\
\text { С, мг\% }\end{array}$} & \multicolumn{3}{|c|}{ Сахара, \% } & \multirow{2}{*}{$\begin{array}{c}\text { Нитраты, } \\
\text { мг/кг }\end{array}$} \\
\hline & & & Моно- & ди- & сумма & \\
\hline Контроль & 5,8 & 10,2 & 2,20 & 0,10 & 2,30 & 167 \\
\hline $\begin{array}{l}\text { Силиплант, } \\
0,8 \text { л/га }\end{array}$ & 5,5 & 8,9 & 2,41 & 0,50 & 2,91 & 154 \\
\hline $\begin{array}{l}\text { Силиплант, } \\
1,0 \text { л/га }\end{array}$ & 5,9 & 12,5 & 2,52 & 0,74 & 3,26 & 162 \\
\hline $\begin{array}{l}\text { Силиплант, } \\
1,2 \text { л/га }\end{array}$ & 6,2 & 12,2 & 2,50 & 1,02 & 3,52 & 160 \\
\hline
\end{tabular}

и снижались темпы распространения болезни по сравнению с контролем. Результаты учетов представлены в табл. 1. Лучший результат был получен при обработках растений Силиплантом (1,2 л/га) в сочетании с Фармайодом. В этом варианте опыта степень развития мучнистой росы была в 4,3 раза меньше, чем в контроле, и составила 15,1\%. По сравнению с контролем инфекция подавлялась на $76,8 \%$, что было на уровне эталона $(78,2 \%)$. Под воз- действием обработок отмечено повышение урожайности огурца на 8,5$17,0 \%$. Наибольшая прибавка к контролю была получена на варианте Силиплант, 1,2 л/га + Фармайод $0,02 \%$.

\section{Обработки}

растений

Силиплантом обеспечили не только снижение потерь урожая от мучнистой росы, но и повлияли на качество продукции. На вариантах с применением Силипланта в норме 1,0-1,2 л/га отмечено повышение в плодах огур-

\section{Библиографический список}

1.Государственный каталог пестицидов и агрохимикатов, разрешенных к применению на территории Российской федерации. Ч. 1. М., 2020. 853 с.

2.Будынков Н.И. Эффективность препарата Рапсол Экстра против мучнистой росы огурца в теплицах // Гавриш. 2014. №2. C. 24-27.

3.Juares M.G., Rosha J.F., Angulo T.P. Alternativas para el control de la cenicilla (Oidium sp.) en pepino (Cucumis sativus L.) // Revista Mexicano der Ciencias Agricolas. 2012. Vol. 3. №2. Pp. 259-270.

4.Juares M.G. et al. Sales minerales et control de la cenicilla (Oidium sp.) en pepino // Revista Mexicano der Ciencias Agricolas. 2016. Vol. 7. №7. Pp. 1551-1561.

5.Dorais M., Theriault M. Beneficial effects of using silicon for organic greenhouse cucumber // Acta Horticulturae. 2018. Vol. 1227. Рp. 443-448.

6.Полифункциональный кремний в растении / И.Г. Тараканов, Л.А. Паничкин, И.М. Коноваленко, Е.Д. Абрашкина // Картофель и овощи. 2019. №12. С. 14-16. http://doi.org/10.25630/ PAV.2019.22.76.004

7.Янишевская О.Л., Дорожкина Л.А. Применение кремнийсодержащих удобрений и регуляторов роста «Эпин-экстра» и «Циркон» при выращивании овощных культур в защищенном грунте // Теплицы России. 2007. №4. С. 38-41.

8.Дорожкина Л.А., Габдрахманов И.Х., Хадеев Т.Г. Рекомендации по применению регуляторов роста в технологии выращивания картофеля. Казань, 2012. 48 с.

9.Литвинов С.С. Методика полевого опыта в овощеводстве. М., 2011. 679 с.

10.Методические указания по регистрационным испытаниям фунгицидов в сельском хозяйстве / Под ред. В.И. Долженко. СПб.: ВИЗР, 2009. 378 с. ца витамина C и сахаров соответственно на 19,6-22,5\% и 41,7-53,0\% по сравнению с контролем (табл. 2). Содержание нитратного азота в продукции во всех вариантах опыта было значительно меньше значения ПДК, которое составляет для огурца защищенного грунта 400 мг/кг сырой массы. Отмечены высокие вкусовые качества продукции.

\section{Выводы}

Таким образом, применение Силипланта в норме расхода 1,0-1,2 л/га в условиях высокого инфекционного фона снижало распространение болезни в теплице. Наиболее эффективную защиту огурца от мучнистой росы обеспечили обработки растений Силипланта в норме 1,2 л/га с добавлением фармайода (0,02\%). В связи с этим Силиплант может быть использован как элемент комплексной системы защиты огурца от мучнистой росы.

\section{References}

1.State catalog of pesticides and agrochemicals permitted for use on the territory of the Russian Federation. Part 1. Moscow, 2020. 853 p. (In Russ.).

2.Budynkov N.I. Effectiveness of Rapsol Extra against cucumber powdery mildew in greenhouses. Gavrish. 2014. №2. Pp. 24-27 (In Russ.).

3.Juares M.G., Rosha J.F., Angulo T.P. Alternatives for the control of Oidium (Oidium sp.) in pepino (Cucumis sativus L.). Mexican journal of agricultural Sciences. 2012. Vol. 3. №2. Pp. 259-270 (In Spanish).

4.Juares M.G. et al. Mineral salts and Oidium control (Oidium sp.) in cucumber. Mexican journal of agricultural Sciences. 2016. Vol. 7. №7. Pp. 1551-1561 (In Spanish).

5.Dorais M., Theriault M. Beneficial effects of using silicon for organic greenhouse cucumber. Acta Horticulturae. 2018. Vol. 1227. Pp. 443-448.

6.Polyfunctional silicon in the plant / I.G. Tarakanov, L.A. Panichkin, I.M. Konovalenko, E.D. Abrashkina. Potato and vegetables. 2019. №12. Pp. 14-16. http://doi.org/10.25630/PAV.2019.22.76.004 (In Russ.).

7.Janishevskaja O.L., Dorozhkina L.A. Application of siliconcontaining fertilizers and growth regulators EPIN-extra and Zircon for growing vegetables in protected soil // Greenhouses of Russia. 2007. №4. Pp. 38-41 (In Russ.).

8.Dorozhkina L.A., Gabdrahmanov I.H., Hadeev T.G. Recommendations for the use of growth regulators in potato growing technology. Kazan', 2012. 48 p. (In Russ.).

9.Litvinov S.S. Method of field experience in vegetable growing. Moscow, 2011. 679 p. (In Russ.).

10. Guidelines for registration tests of fungicides in agriculture / Ed. by V.I. Dolzhenko. Saint Petersburg: ARRIP, 2009. 378 p. (In Russ.).

\section{Об авторах}

Алексеева Ксения Леонидовна, доктор с.-х. наук, Г.н.с., ВНИИО - филиал ФГБНУ ФНЦО. E-mail: vniioh@yandex.ru

Сметанина Лариса Геннадьевна, канд. с.-х. наук, с.н.с., ВНИИО - филиал ФГБНУ ФНЦО. E-mail: vniioh@yandex.ru

\section{Author details}

Alexeeva K.L., Doctor Sci. (Agr.), chief research fellow, AllRussian Research Institute of Vegetable Growing - a branch of Federal Scientific Centre of Vegetable Growing (ARRIVG - a branch of FSBSI FSCVG). E-mail: vniioh@yandex.ru

Smetanina L.G., Cand. Sci. (Agr.), senior research fellow, ARRIVG - a branch of FSBSI FSCVG. E-mail: vniioh@yandex.ru 